- ORIGINAL ARTICLE

Volume 9 Issue 42017

DOI: 10.21315/eimj2017.9.4.5

ARTICLE INFO

Submitted: 19-7-2017

Accepted: 19-11-2017

Online: 29-12-2017

\section{The Challenges of Bioethics Teaching to Mixed- Ability Classes of Health Sciences Students}

\author{
Sabreena Safuan, Siti Hawa Ali, Garry Kuan, Idris Long, Nik Norliza \\ Nik Hassan
}

School of Health Sciences, Universiti Sains Malaysia, MALAYSIA

To cite this article: Safuan S, Ali SH, Kuan G, Long I, Nik Hassan NN. The challenges of bioethics teaching to mixed-ability classes of health sciences students. Education in Medicine Journal. 2017;9(4):41-49. https://doi.org/10.21315/eimj2017.9.4.5

To link to this article: https://doi.org/10.21315/eimj2017.9.4.5

\title{
ABSTRACT
}

Introduction: Bioethics subject which is part of the curriculum in higher education has a slightly different orientation compared to the science subjects. This study investigates the challenges of teaching bioethics subject to the health sciences students and the outcome of using mixed educational background classes in bioethics. Methods: Discussions among lecturers of bioethics were conducted to determine the possible challenges when teaching bioethics to the health sciences students who are accustomed to the format of science subjects. Results of written bioethics tests (multiple choice questions [MCQs] versus short essays) were also analysed among students from nine different health sciences background (biomedical sciences, nursing, speech pathology, dietetics, nutrition, medical radiation, audiology, sports science, and occupational safety and health) as a measure of the students' understanding of the bioethics subject. Findings: The challenges of bioethics teaching were divided into five categorical themes; (i) attitude/discipline, (ii) background knowledge, (iii) reasoning/critical thinking, (iv) knowledge/jargon, and (v) diverse educational background. Excellence performances were demonstrated by the students across the ten disciplines in the direct MCQs while they did very poorly $(p<0.01)$ in the critical thinking short essay questions. Conclusions: Bioethics proof to be a challenging subject for the health sciences students as this subject deal with complex issues of ethical concerns which differ with most science subjects. Combined efforts of the educators and students are needed in order to address these challenges and stimulate the understanding of bioethics.

\section{Keywords: Bioethics, Health Sciences, Mixed-ability class, Challenges}

Sabreena Safuan, School of Health Sciences, Universiti Sains Malaysia, Health Campus, Kubang Kerian, 16150 Kota Bharu, Kelantan, Malaysia | Email: sabreena@usm.my

\section{INTRODUCTION}

Ethics is a sub-branch of philosophy field seeking the right and wrong in given circumstances (1). In an ethical discussion, an individual seeks to determine the good and the bad side of a decision with supporting reasons. Bioethics on the other hand is the study about the norm of right and wrong in the field of medicine and health sciences (2). It provides a guideline on the appropriate actions to be taken in a given situation. The discussion on bioethics integrated the theory, principles and the legal consequences of an action and decision.

Health Sciences is a field of science that actively combined the used of science, technology, engineering and mathematics in diseases and health care deliveries. This multidisciplinary field aims to improve the holistic health and well beings of both humans and animals. Health sciences 
contribute to the body of knowledge mostly via research, theoretical applications and documentations. The factors which impact health, etiology of diseases, and the risk factors and diagnosis, were discovered in this field through research and these were eventually translated into the clinical settings. The disciplines of health sciences include anatomy, physiology, pathology, immunology, virology, dietetics, and various other sub-disciplines related to applied sciences.

Bioethics course is commonly integrated into the curriculum of most universities producing health sciences students (36 ). The subject of bioethics itself is very challenging especially to the sciences students that are used to logical and straight thinking based on given facts. In bioethics, students are expected to engage in critical thinking and rigorous discussions of a given issue. Unlike pure sciences subjects, there are no right and wrong answers in bioethics. Students can take different stands however with the correct reasoning and arguments. They must provide strong justifications for their stand while bearing in account the justifications from the opposite side. Teachers or lecturers act as the facilitators to stimulate discussions and active thinking in classes. These alone prove difficult to the majority of health sciences students as they are used to memorising hard facts and reiterate them during the exam. In addition, the questions format differs between bioethics and sciences subjects, which provides an additional challenge to the health sciences students (7). The straight forward facts-based questions in science subjects are usually in a multiple-choice question (MCQ) format or short essays. In bioethics, questions are usually case-based in short essay or long essay formats where students will be expected to analyse the given situations.

In the School of Health Sciences, various science disciplines will be placed under the same management system. Certain common subjects such as bioethics will usually be shared by the various courses and it is a norm to combine the students in one big class. Meaning that students from different sub-disciplines of health sciences will share the same time slots and the same teaching approaches regardless of the educational backgrounds, skills, interests and learning abilities. This class is known as the mixedability class or heterogeneous class. The higher heterogeneity level of a class, the more challenging it is for the educators.

The first objective of this paper is to explore the challenges faced in the teaching and learning of bioethics to the mixed-ability class of the health sciences students which are accustomed to learning sciences. The second objective highlights the students' performance based on the different format of exam questions, based on the same teaching approaches in the mixed-ability class. This study is important to identify current challenges and problems of this philosophical-based course towards the best design of bioethics curriculum for the health sciences students.

\section{METHODOLOGY}

\section{Sample Population}

This study is a mixed methods study design. The first part involved a cross sectional study involving the third year students from the School of Health Sciences, Universiti Sains Malaysia. The second part involved a focus group discussion among the educators of bioethics course. Currently, bioethics course is offered to all third year students in the School of Health Sciences. The students were from nine difference health sciences courses namely Biomedical Science ( $\mathrm{n}=$ 42), Sports Science $(n=25)$, Nutrition ( $n$ $=34)$, Dietetics $(n=30)$, Environment and Occupational Health ( $\mathrm{n}=24)$, Nursing ( $\mathrm{n}=$ 27), Medical Radiation ( $\mathrm{n}=24$ ), Audiology $(\mathrm{n}=18)$ and Speech Pathology $(\mathrm{n}=10)$. The total cohort of this study was 234 . The mean age was 23.78 (range: 22 to 43 ), with 55 male and 179 female students. 


\section{Challenges of Bioethics Teaching to the Health Sciences Students}

The students from the nine different courses were exposed to the same teaching methods by five different lecturers of bioethics. Conventional styled lectures were given to the students in one big lecture hall. The duration of each lecture was one hour, conducted twice in a week for a total of 12 weeks. Tutorial classes were also conducted once a week for one hour in a tutorial room where students were divided according to their respective courses, also for the duration of 12 weeks.

After 12 weeks, a one-hour discussion was carried out involving the five lecturers of bioethics. The focus was on the main problems and challenges faced when conducting bioethics classes to these students of health sciences. The main challenges faced were recorded and categorised into different themes. Therefore, for the analysis of the qualitative data, the method of content analysis with categorical thematic was chosen.

\section{Outcomes of Bioethics Teaching on the Mixed Ability Classes of Health Sciences Students}

Written assessments were conducted to assess the ability of the mixed classes towards the teaching approaches. The assessments also measure students understanding and data were categorised based on each sub-discipline in health sciences. These cohorts sat two different tests; Test 1 where the questions were a standard direct objective questions (MCQ) similar to the format of science subjects and Test 2 questions are application and critical thinking essay questions.

Data were analysed using GraphPad Prism Version 7.00 for Windows (La Jolla California, USA) and Microsoft Excel 2017. One-way ANOVA was used to analyse the differences in performance between sub- disciplines. A $p$ value less than 0.01 , twotailed was considered significant.

\section{FINDINGS}

\section{Challenges of Bioethics Teaching to the Health Sciences Students}

In the focus discussion among the educators of bioethics, there are significant challenges identified when teaching bioethics to the health sciences students of various sub-disciplines. These challenges where categorised into five themes. The five categorical themes and their illustrative issues were summarised in Table 1.

\section{Outcomes of Bioethics Teaching on the Mixed Ability Classes of Health Sciences Students}

Figure 1 shows the average bioethics test scores based on the direct questions MCQ format from nine different sub-disciplines of health sciences. All sub-disciplines recorded the scores of more than $60 \%$ and there was no significant difference on the scores recorded except for the sport sciences students (average $66.96 \pm 2.08$ ) and nursing (average 67.28 \pm 1.65 ).

Figure 2 shows the average bioethics test scores of the case study-based essay format from the nine different sub-disciplines of health sciences. All sub-disciplines recorded the score of less than $50 \%$ except for Dietetics sub-discipline with the score of $53.00 \pm 2.07$. Medical Radiation subdiscipline shows the lowest score of $24.58 \pm$ 2.49 .

Figure 3 compares the test scores of MCQ and essay questions from the nine subdisciplines of health sciences. Across the nine sub-disciplines, the results were consistence in each discipline; all students scored significantly better in the direct MCQ questions compared to the case studybased essay questions $(p<0.01$ for all). 
Table 1: The categorical themes on the challenges of bioethics teaching and learning to various subdisciplines of health sciences students and their illustrative issues

\begin{tabular}{|c|c|c|}
\hline No. & Categorical theme & Illustrative issue \\
\hline 1. & $\begin{array}{l}\text { Attitudes/ } \\
\text { Disciplines }\end{array}$ & $\begin{array}{l}\text { This course was offered as a compulsory elective course to the science students. } \\
\text { Naturally, students viewed this course as having relatively lower value than their } \\
\text { core courses. Therefore, their attitude/disciplines towards this course is less than } \\
\text { the core courses. }\end{array}$ \\
\hline 2. & $\begin{array}{l}\text { Background } \\
\text { knowledge }\end{array}$ & $\begin{array}{l}\text { There was an insufficient time to gain in-depth knowledge based on the } 2 \\
\text { hours a week classes (plus one-hour tutorial slot). Students with little bioethics } \\
\text { background were encouraged to do some background reading outside the class. } \\
\text { However most of them failed to do so. They depend on the notes given in the } \\
\text { classes which are not sufficient. }\end{array}$ \\
\hline 3. & $\begin{array}{l}\text { Reasoning and } \\
\text { critical thinking }\end{array}$ & $\begin{array}{l}\text { Majority of the health sciences students are lacking critical thinking and reasoning } \\
\text { per case basis as they are used to memorising theories taught in classes with } \\
\text { minor arguments. Most of the sciences theories are hard facts proven by strong } \\
\text { experimental data. This proves difficult in bioethics classes as bioethics teaching } \\
\text { will lead to arguing certain facts with justifications especially when discussing } \\
\text { case study. Therefore, educators in bioethics should encourage this thought } \\
\text { process better. }\end{array}$ \\
\hline 4. & $\begin{array}{l}\text { Language and } \\
\text { jargon }\end{array}$ & $\begin{array}{l}\text { The jargons and words used in bioethics are different from the jargons used } \\
\text { in health sciences subjects. Therefore, extra efforts and reading materials } \\
\text { are required to translate these ethical jargons into understandable technical } \\
\text { vocabularies. }\end{array}$ \\
\hline 5. & $\begin{array}{l}\text { Diverse } \\
\text { educational } \\
\text { background and } \\
\text { class size }\end{array}$ & $\begin{array}{l}\text { The bioethics class, being a common elective subject taken by all sub-discipline } \\
\text { of health sciences, is a heterogeneous class. Mainly, student differs in term of } \\
\text { their educational background which made this a challenging cohort to cater. } \\
\text { They have different learning preferences and learning styles. They also differ in } \\
\text { term of the level of knowledge and understanding. The size of the class is also } \\
\text { very challenging making this hard to the lecturer to cater for individual needs. } \\
\text { Tutorial sessions, although helpful as these students were divided based on their } \\
\text { sub-disciplines are not enough to stimulate critical thinking among the students. }\end{array}$ \\
\hline
\end{tabular}

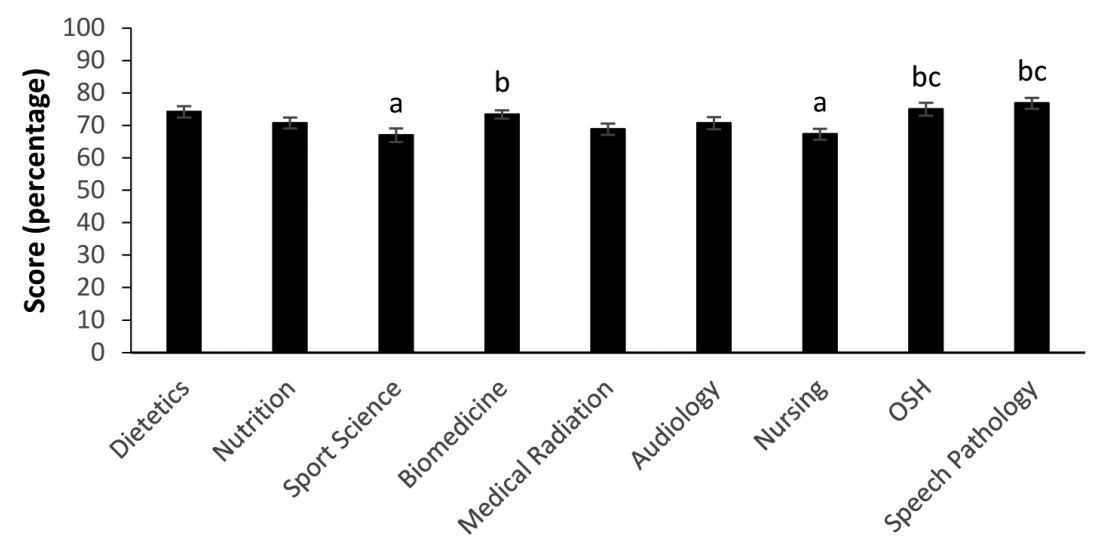

Sub-discipline of Health Sciences

Figure 1: Bioethics test scores (direct MCQ format) from nine different sub-disciplines of health sciences students.

Note: a - significant difference compared to nutrition sub-discipline; b - significant difference compared to sports science sub-discipline and c - significant difference compared to nursing sub-discipline.

The level of significant; $p<0.01$. 


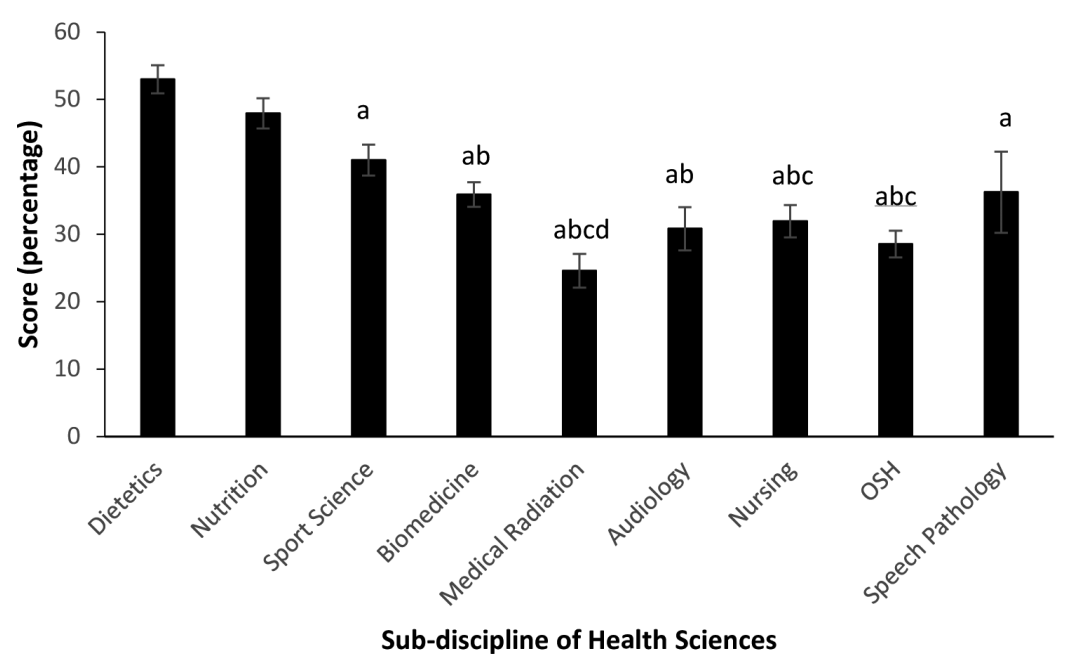

Figure 2: Bioethics test scores (case study-based essay format) from nine different sub-disciplines of health sciences students.

Note: a - significant difference compared to dietetics sub-discipline; b - significant difference compared to nutrition subdiscipline; c - significant difference compared to sports science sub-discipline; and d - significant difference compared to biomedical science sub-discipline.

The level of significant; $p<0.01$.

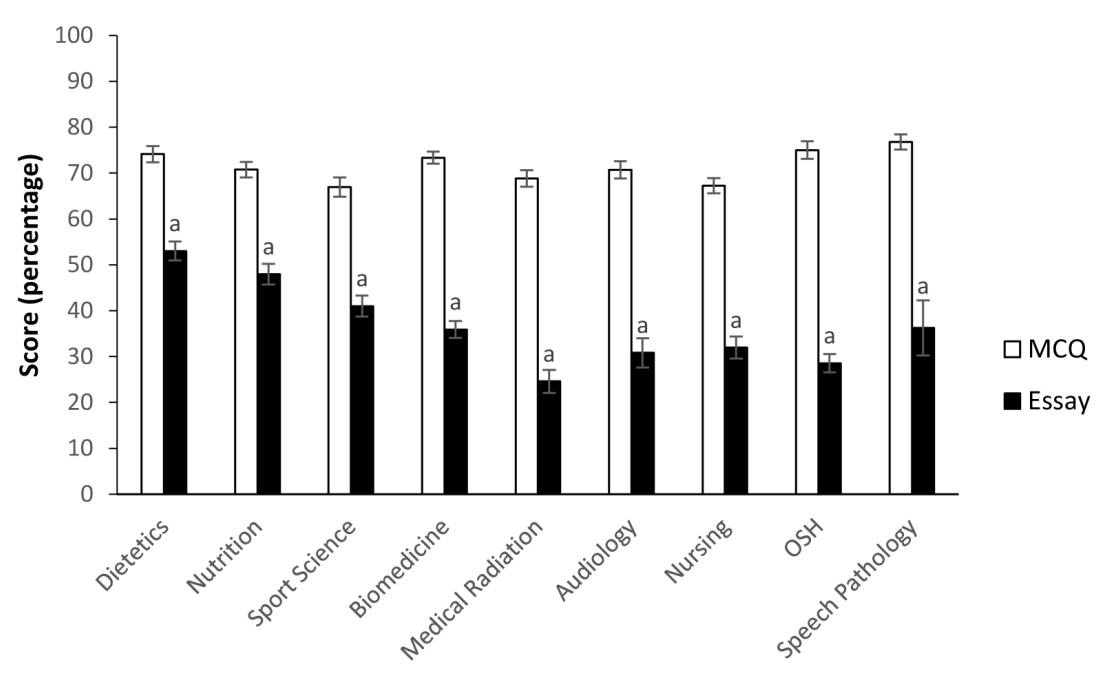

Sub-discipline of Health Sciences

Figure 3: Bioethics test scores comparing the direct MCQ format with the case study-based essay format from nine different sub-disciplines of health sciences students.

Note: a - significant difference comparing between the two different format.

The level of significant; $p<0.01$.

\section{DISCUSSIONS AND CONCLUSIONS}

The teaching and learning of bioethics are important as this subject teaches students to make important ethical decisions in everyday situations with the highest morality and integrity. In health sciences, bioethics is an important aspect as these students will learn about the protection of patients' and clients' best interest when they join the workforce while balancing between autonomy and responsibilities. In bioethics, students also learn to be responsible towards their decisions. 
Teaching bioethics to students of health sciences come with huge responsibilities and bigger challenges. Some even argue that it is unrealistic to expect science teachers or lecturers to address moral and ethical aspects of science (8). The best person to teach is a philosopher. This is because health science describes material world whereas ethics deal with an action based on given knowledge. Thus, the skills and knowledge to teach ethics differ from those needed to teach health sciences subjects. However, it could be argued that, although philosophers are considered as masters in this field, the link between ethics and health sciences would be missing if they were to teach bioethics. In any higher institutions, the science curriculum is very pack resulting to the students to think that ethical courses are less important compared to their contentloaded core courses. Therefore, teachers with blended knowledge in ethics and sciences would be an advantage.

In this study, based on the focus discussion, five main challenges of bioethics teaching were identified. These include the (i) lack of attitudes, (ii) no background knowledge, (iii) lack critical reasoning skills, (iv) difficulty in understanding technical jargon, and (v) diverse students' background in big classes. These identified challenges are also discussed in other studies $(9,10)$ meaning that they are the universal challenges that should be address when developing bioethics curriculum. In order to cater to these issues, teachers or lecturers involved must be able to stimulate and enhance interest in bioethics among students. Perhaps, discussion and engagement of contemporary and current issues might arouse students' interest. With this, they learn to incorporate their knowledge of health sciences and learn that understanding health science precedes ethical decisions making. If students' interest in bioethics could be stimulated, the attitude towards ethics course might change towards the positive side and the challenges listed above will resolve. In fact, studying bioethics is beyond conventionally styled lectures; a more interactive lesson plan should be developed. Different types of teaching methods could be used in ethics teaching. This is in accordance to another study which concluded that case discussion and using video as a teaching tool is the most effective means of learning ethics compared to power point presentations (11). In case discussion, students are able to contrast their different views during the short discussion group session. This method, well used at other teaching universities and ours was proven to stimulate interest and though processes better $(12,13)$.

In addition, the educators have to be able to stimulate active discussion among students. In our experience, students tend to keep to themselves during the discussion sessions especially when they are not confidence enough to argue certain points. However, students are more attentive and is not afraid to join in the class discussion in a similar study conducted in the United States (14, 15) and India (11). Therefore, whether this issue is related to ethnicity and cultural values remains to be studied. Maybe, issues discussed in class should be interesting and close to the students' heart to engage in active discussion. Real cases could also be discussed to encourage reasoning and most importantly, the values reflected on these cases and the take home message should be embedded in the students.

Mixed ability classes of bioethics must be dealt with extra effort. In bioethics class, it is hard to ascertain that all students are learning effectively. Individual progress is hard to track and a balance in students' participation will be hard to control. Certain individuals or sub-disciplines will dominate. The domination is reflected from the results of the case study-based essay questions in this study. Certain courses recorded higher scores with a large disparity with other health sciences sub-disciplines. In order to deal with this imbalances, lecturers should be aware that there are different learning styles that best suit difference sub-discipline and individual student; visual style, auditory learning and kinesthetic approaches (16). 
The teaching style or slides presentation should accommodate the differences of the learning styles. In addition, asking specific questions, pair work, grouping or using specific materials are good ways of engagement (17). Lecturers should know the students' educational background and give examples in class that truly reflect their disciplines. It was also suggested to separate students based on their learning ability to improve the teaching and learning performances. However, a study showed that grouping students by ability have limited advantages compared to the mixed-ability classes (18). In the mixed-ability classes, the interactions between students prove to be an asset provided that the educators can nurture this talent (19).

One of the issues in bioethics teaching is the bridging between science courses and philosophy-based course. Of these, the differences in the sciences based questions and the bioethics based question might influence students' performance. The questions format; MCQ versus essay and the nature of the questions; straightforward direct questions versus application and critical thinking questions might prove to be a hurdle to the students. In this study, we showed that students' performance was higher in MCQ-based questions compared to the essay questions. The MCQ questions are categorised under lower order thinking (LOT) questions which are usually straightforward fact-based questions (20). The essay questions are generally in higher order thinking skills (HOTS) category which involved the application of theories and critical appraisal. In health sciences field, fact-based questions dominate with less portion of case-study based questions. In bioethics, higher percentages of questions involved case studies and application (21). Therefore, explanation on the nature of questions should be carried out to the students so that they can prepare themselves accordingly. Exercise and past year questions should be discussed and distributed to the class to encourage the taught progression.
It was shown that students with adequate exercise and exposure to the nature of ethics question scored higher compared to the non-exposed students (22). The question to ask is how many exercises and questions should be discussed with the students to ensure a good performance from the students.

In conclusion, teaching bioethics to health science students is challenging. Although small classes of bioethics are preferable, large heterogeneous large classes of bioethics can be implemented into the health sciences education. However, the educators must be able to stimulate interest in ethics and get the students to participate in the ethical discussions actively. The transfer of bioethical knowledge is vital to produce a well-equipped individual that can balance between professionalism, responsibility, integrity and empathy upon entering the job market.

\section{REFERENCES}

1. Reiss MJ. Introduction to ethics and bioethics. In: Bryant J, la Velle LB, SearleChichester J, editors. Bioethics for scientists. UK: John Wiley \& Sons, Ltd.; 2002. p. 1-17. https://doi. org/10.1002/0470846593.ch1

2. SchÜKlenk UDO. Ethics in bioethics. Bioethics. 2006;20(5):iii-iii. https://doi. org/10.1111/j.1467-8519.2006.00498.x

3. Bryant J, Baggott la Velle L. A bioethics course for biology and science education students. Journal of Biological Education. 2003;37(2):91-5. https://doi.org/10.1080/00 219266.2003.9655858

4. Pearce RS. A compulsory bioethics module for a large final year undergraduate class. Bioscience Education. 2009;13(1):1-21. https://doi.org/10.3108/beej.13.1 
5. Pickersgill MD. Research, engagement, and public bioethics: promoting socially robust science. Journal of Medical Ethics. 2011;37(11):698-701. https://doi. org/10.1136/jme.2010.041954

6. Willison DJ, Ondrusek N, Dawson A, Emerson C, Ferris LE, Saginur R, Sampson $\mathrm{H}$, Upshur R. What makes public health studies ethical? Dissolving the boundary between research and practice. BMC Medical Ethics. 2014;15:61. https://doi. org/10.1186/1472-6939-15-61

7. McDougall R. Systematic reviews in bioethics: types, challenges and value. J Med Philos. 2014;39(1):9. https://doi. org/10.1093/jmp/iht059

8. Downie R, Clarkeburn H. Approaches to the teaching of bioethics and professional ethics in undergraduate courses. Bioscience Education. 2005;5(1):1-9. https://doi.org/ 10.3108/beej.2005.05000003

9. Colon-Gonzales MC, El Rayess F, Guevara S, Anandarajah G. Successess, challenges and needs regarding rural health medical education in continental Central America: a literature review and narrative synthesis. Rural Remote Health. 2015;15(3):3361.

10. Ekmekci PE, Oral M, Yurdakul ES. A qualitative evaluation of ethics educational program in health science. Medicine and Law. 2015;34(2):217-28.

11. Vedavathi H, Tejasvi TS, Revankar SP. Comparative study on teaching of bioethics to health are persons using different methodologies. International Journal of Medical Research and Health Sciences. 2013;2(4):899-904. https://doi. org/10.5958/j.2319-5886.2.4.144

12. Boud D, Walker D. Promoting reflection in professional courses: the challenge of context. Studies in Higher Education. 1998;23(2):191-206. https://doi.org/10.1080 /03075079812331380384
13. Engel-Glatter S, Cabrera LY, Marzouki Y, Elger BS. Teaching bioethics to a large number of biology and pharma students: lessons learned. Ethics \& Behavior. 2016:1-21. https://doi.org/ 10.1080/10508422.2016.1196361

14. Fox E, Arnold RM, Brody B. Medical ethics education: past, present and future. Acad Med. 1995;70(9):761-9. https://doi. org/10.1097/00001888-199509000-00013

15. Eratt TD. Ethics education in undergraduate pre-health programs. The contribution of undergraduate colleges and universities to the ethical and moral development of future doctors in the medical and dental professions. Tex Dent J. 2011;128(8):698706.

16. Heffler B. Individual learning style and the learning style inventory. Educational Studies. 2001;27(3):307-16. https://doi. org/10.1080/03055690120076583

17. Garside C. Look who's talking: a comparison of lecture and group discussion teaching strategies in developing critical thinking skills. Communication Education. 1996;45(3):212-27. https://doi. org/10.1080/03634529609379050

18. Hamsa V, William D. Tracking and mixedability grouping in secondary school mathematics classroom: a case study. British Edu Res J. 2003;29(2):189-204. https://doi. org/10.1080/0141192032000060939

19. Justice C, Rice J, Warry W, Inglis S, Miller $S$, Sammon S. Inquiry in higher education: reflections and directions on course design and teaching methods. Innovative Higher Education. 2007;31(4):201-14. https://doi. org/10.1007/s10755-006-9021-9

20. Krathwohl DR. A revision of bloom's taxonomy: an overview. Theory Into Practice. 2002;41(4):212-18. https://doi.org/10.1207/ s15430421tip4104_2 
21. Miller S, Selgelid MJ. Ethical and philosophical consideration of the dual-use dilemma in the biological sciences. Science and Engineering Ethics. 2007;13(4):523-80. https://doi.org/10.1007/s1 1948-007-9043-4
22. Wade N. Geeting teachers and pupils interested in the really hard questions - an example from physics [cited 2017 September 9]. Available from: http://www. cambridgeassessment.org.uk/insights/arepast-paper-questions-always-useful/ 